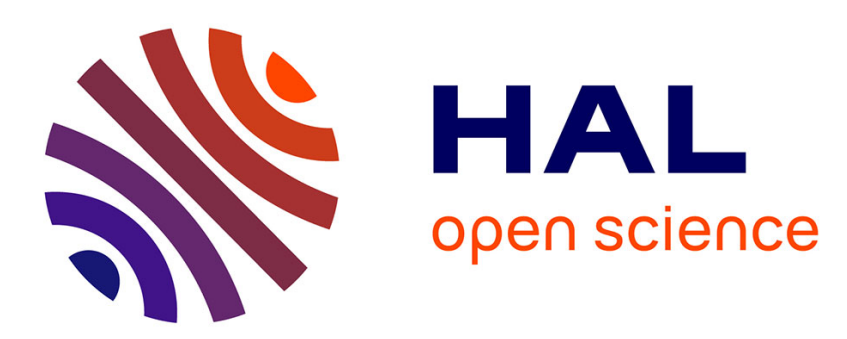

\title{
XAFS Study of the Ce Valence in Magnetic Ce Intermetallic Compounds
}

Olivier Isnard, S. Miraglia, F. Villain

\section{To cite this version:}

Olivier Isnard, S. Miraglia, F. Villain. XAFS Study of the Ce Valence in Magnetic Ce Intermetallic Compounds. Journal de Physique IV Proceedings, 1997, 7 (C2), pp.C2-1191-C2-1192. 10.1051/jp4:19972188 . jpa-00255257

\section{HAL Id: jpa-00255257 https://hal.science/jpa-00255257}

Submitted on 1 Jan 1997

HAL is a multi-disciplinary open access archive for the deposit and dissemination of scientific research documents, whether they are published or not. The documents may come from teaching and research institutions in France or abroad, or from public or private research centers.
L'archive ouverte pluridisciplinaire HAL, est destinée au dépôt et à la diffusion de documents scientifiques de niveau recherche, publiés ou non, émanant des établissements d'enseignement et de recherche français ou étrangers, des laboratoires publics ou privés. 


\title{
XAFS Study of the Ce Valence in Magnetic Ce Intermetallic Compounds
}

\author{
O. Isnard, S. Miraglia and F. Villain* \\ Laboratoire de Cristallographie, CNRS, BP. 166X, Université J. Fourier, 38042 Grenoble, France \\ * Laboratoire LURE, Bât. 209D, Université Paris Sud, 91405 Orsay, France
}

\begin{abstract}
We report on the XAFS analysis of the valence state of $\mathrm{Ce}$ in intermetallic compounds whose structure is of $\mathrm{ThMn}_{12}$ type. $\mathrm{Ce}$ is known to exhibit different valence state in intermetallic phases. Here we focus on iron-based Ce compounds, known for their prospective magnetic properties. We have studied the influence of iron substitution by non magnetic elements such as $\mathrm{Ti}$, $\mathrm{Ga}$, $\mathrm{Al}$ on the electronic state of cerium. The $\mathrm{Ce}_{3}$ absorption edge XAFS is measured using the DCI synchrotron radiation facility at LURE. The spectra are discussed in terms of the change in the $\mathrm{Ce}$ valence as the result of progressive substitution of iron. The main magnetic properties are briefly presented.
\end{abstract}

\section{INTRODUCTION}

The rare earth transition metal intermetallic compounds are the matter of many studies nowadays. They offer the advantage to combine the properties of transition metals (delocalized magnetism) with those of the rare earth (localized magnetism due to the $4 \mathrm{f}$ shell). Among the potential applications of these intermetallics, one can underline hard magnetic materials, magnetostriction, magnetooptics. Here we report on iron rich intermetallics studied for their hard magnetic properties.

The rare earth -iron phase diagram exhibits many crystalline phases with a variety of crystal structures depending on the stoichiometry. The RFe12 phase does not exist as such, however the ThMn12 type of structure can be stabilized by substituting $d$ or $p$ elements to iron [1]. Among the rare earth elements cerium is often observed to exhibit a peculiar behaviour because of its intermediate valence character. In the ThMn12-type structure, the rare earth element is found to sit on one site only. Another advantage of this structure lies in the wide variety of elements than can be substituted to iron; this enables to modify in a tailor-made fashion the cerium environment while keeping the same crystal structure. Here we have chosen the

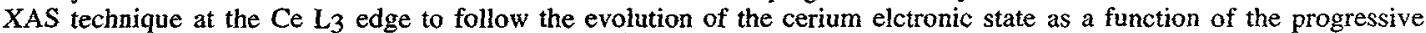
substitution of iron by other elements.

\section{EXPERIMENTAL DETAILS}

Information and details on the samples preparation can be found in reference [2]. The XAS experiments were performed at the DCI synchrotron radiation storage ring at LURE (Orsay), on the EXAFS 3 experimental station. The monochromator consisted of two parallel Si crystals cut along the (311) plane. The rejection of harmonics was made by adjusting the parallelism between the crystals. The detectors were two ionization chambers filled with air. The energy of the Ce L3 edge was calibrated against that of the $\mathrm{Cr} \mathrm{K}$ edge.

A calibrated amount of powder sample was mixed with cellulosis in order to optimize the edge jump. All absorption spectra were normalized to the edge jump. The data collection was made using a step of $0.3 \mathrm{eV}$. The determination of the valence has been performed using a deconvolution technique from the $\mathrm{L}_{3}$ spectra recorded at room temperature. The deconvolution process is based on a artan function which describes the transition from the $2 p$ to the continuum states and a Lorentzian function that takes into account both the $5 \mathrm{~d}$ density of unoccupied states and the finite lifetime of the $2 \mathrm{p}$ core hole. The equation which is used is taken from Röhler $[3,4]$.

\section{RESULTS AND DISCUSSION}

We have summarized in table 1 the main structural and magnetic relevant parameters as well as the fit cerium valence. We have also represented on figure 1 and 2 the XAS spectra of $\mathrm{CeFe}_{11} \mathrm{Ti}$ and $\mathrm{CeFe}_{4} \mathrm{Al} 8$.

\begin{tabular}{|c|c|c|c|c|c|}
\hline Sample & $\mathbf{a}(\AA)$ & $c(\AA)$ & $T_{c}(K)$ & $\begin{array}{c}\mathrm{M}_{\mathrm{S}}\left(\mu_{\mathrm{B}} / \mathrm{f} . \mathrm{u}\right) \\
\text { at } 4 \mathrm{~K}\end{array}$ & valence \\
\hline $\mathrm{CeFe}_{4} \mathrm{Ga}_{8}$ & $8.764(5)$ & $5.095(4)$ & 280 & 7.3 & $3.10(2)$ \\
\hline $\mathrm{CeFe}_{5.5 \mathrm{Ga}} 6.5$ & $8.764(1)$ & $4.999(1)$ & 372 & 9.6 & $3.14(2)$ \\
\hline $\mathrm{CeFe}_{4} \mathrm{Al}_{8}$ & $8.8052(2)$ & $5.0482(2)$ & 160 & 0.3 & $3.19(2)$ \\
\hline $\mathrm{CeFe} 11 \mathrm{Ti}$ & $8.5396(7)$ & $4.7799(5)$ & 487 & 16.1 & $3.33(2)$ \\
\hline
\end{tabular}

Table 1 Lattice parameters, magnetic data and fit valence of selected $\mathrm{CeFe}_{12-\mathrm{X}} \mathrm{M}_{\mathrm{X}}$ compounds

The spectrum of the $\mathrm{CeFe}_{11} \mathrm{Ti}$ compound is characterized by a clear splitting of the white line that can be associated to the $4 \mathrm{f}^{1}$ and $4 \mathrm{f}^{0}$ channels, this shows that cerium is in an interemediate valence state. The fit to the spectrum yielding the valence 
values $v=3.334$ which is another clear indication It can be seen from table 1 that the progressive subsitution of iron by other elements leads to a relocalization of the $4 f$ states of cerium.

It is worth noticing that a strong $4 \mathrm{f}^{1}$ character is observed in the case of the $\mathrm{CeFe}_{4} \mathrm{Ga} 8$ compound. In this respect a very interesting comparison can be made with the hydrogenated compounds in this system $[5,6]$, which shows that iron substitution is more effective than hydrogenation to relocalize the $4 \mathrm{f}$ states.

The coordination of cerium in the $\mathrm{CeFe} 12-\mathrm{x} \mathrm{M}_{\mathrm{X}}$ system is composed of 20 atoms [7] that can be decomposed in $8+8+4$ that sit respectively on the $8 \mathrm{j}, 8 \mathrm{f}$ and $8 \mathrm{i}$ sites (Wyckoff notation) of the $14 / \mathrm{mmm}$ space group. Neutron diffraction has allowed to derive the substitution scheme in these compounds. It has been shown that the substitution for iron takes place first on the $8 \mathrm{i}$ sites that is on the first neighbours. This means that in the case of $\mathrm{Al}$ and $\mathrm{Ga}$ substitution we cannot exclude a $4 \mathrm{f}$ (Ce)-p (Al$\mathrm{Ga}$ ) hybridization in order to account for the changes of the electronic state of cerium

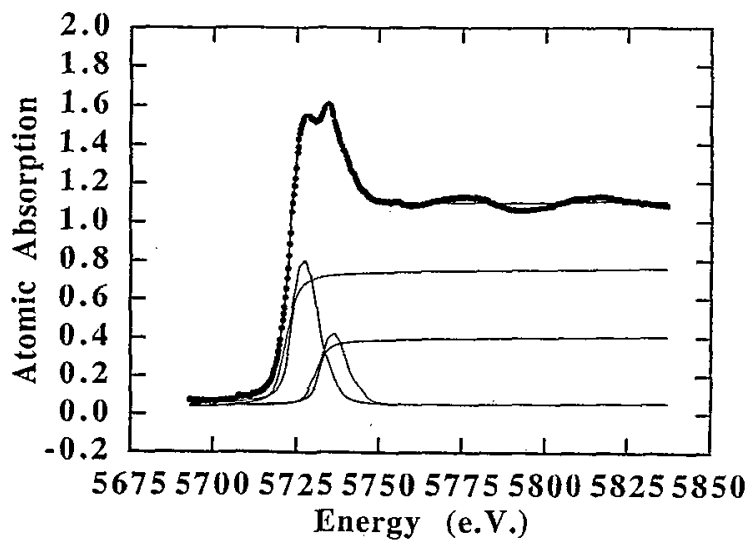

Figure 1 : XANES signal recorded at the $\mathrm{Ce}_{\mathrm{L}}$ edge in $\mathrm{CeFe} 11 \mathrm{Ti}$ along with model decomposition in $4 \mathrm{f}^{1}$ and $4 \mathrm{f}^{0}$ contributions.

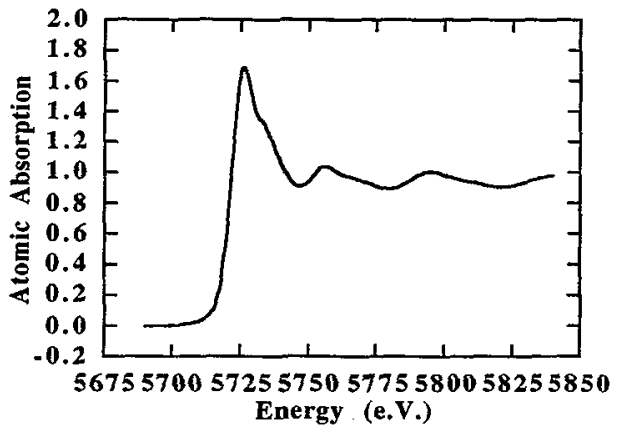

Figure 2: $\mathrm{XANES}$ signal recorded at the $\mathrm{Ce}_{3}$ edge in $\mathrm{CeFe}_{4} \mathrm{Al}_{8}$ at $\mathrm{T}=9 \mathrm{~K}$.

\section{CONCLUSION}

This study has shown that in the CeFe12-x $\mathrm{M}_{\mathrm{X}}$ system, the valence of cerium is very sensitive to the substitution of of iron by other $\mathrm{d}$ or $\mathrm{p}$ elements. This investigation by means of XAS at the $\mathrm{Ce} \mathrm{L}_{3}$ edge has shown that in the $\mathrm{Ce}_{2} \mathrm{Fe}_{12-\mathrm{x}} \mathrm{M}_{\mathrm{X}}$ system, cerium remains in an intermediate valence state rather than undergoing a non magnetic $\left(\mathrm{Ce}^{4+}\right)$ to magnetic $\left(\mathrm{Ce}^{3+}\right)$ transition.

References :

[1] F. de Boer, Y.K Huang, D.B. de Mooij, K.H.J. Buschow, J. Less Common Met. 135 (1987) 199-204.

[2] E. Tomey, O. Isnard, A. Fagan, C. Desmoulins, S. Miraglia, J.L. Soubeyroux, D. Fruchart Journal of Alloys and Compounds 191 (1993) 233-238.

[3] J. Röhler, J; Magn. Magn. Mater.47 (1985) 175-180.

[4] J. Röhler in Handbook on the physics and chemistry of rare earths, Vol 10, Eds K.A. Gschneider, J.LR. Eyring, S. Hufner, pp 453-544, Elsevier Science Publisher (1987).

[5] J. Chaboy, A. Marcelli, L. Bozukov, F. Baudelet, E. Dartyge, A. Fontaine, S. Pizzini Phys. Rev. B51 (1995) $9005-9014$.

[6] O. Isnard, S. Miraglia, C. Giorgetti, F. Baudelet, E. Dartyge, G. Krill, D. Fruchart in this conference

[7] J.V. Florio, R.E. Rundle, A. Snow, Acta Cryst. 5 (1952) 449-457. 